\title{
Examining the Link Between Funding and Intellectual Interventions Across Universities and Think Tanks: a Theoretical Framework
}

\author{
Marcos Gonzalez Hernando $^{1,2}$ • Kate Williams ${ }^{2}$
}

Published online: 14 March 2018

(C) The Author(s) 2018

\begin{abstract}
Policy-oriented expert knowledge is increasingly applied, collaborative and socially accountable, created in a variety of organisations and institutions that display a diversity of funding patterns with a wide range of requirements and expectations. Given the complexities of knowledge production and recent changes in its funding environment (e.g. mode and availability of research funding and evaluation), few existing theoretical elaborations consider tensions between structural funding conditions and intellectual production in policy research contexts. This paper examines the role of funding in shaping the policy issues, format and content of intellectual output across two research contexts (universities, think tanks). It sets out a theoretical and methodological approach to understand the link between funding modalities and the type of knowledge and intellectual interventions they facilitate or thwart.
\end{abstract}

Keywords Funding $\cdot$ Intellectual interventions $\cdot$ Knowledge $\cdot$ Sociology of organisations

\section{Introduction}

This paper examines how the funding of policy research organisations affects the shape and content of the knowledge they produce. Its main objective is to propose a theoretical and methodological framework that sheds light on the process of producing policy-relevant intellectual interventions, with an accent of the place of funding modalities and sources within it. In other words, it will both provide a model to interpret the locus of funding pressures in the

Marcos Gonzalez Hernando

mjg221@cam.ac.uk

Kate Williams

khw26@cam.ac.uk

1 Department of Sociology, City, University of London, Northampton Square, London EC1V 0HB, UK

2 Department of Sociology, University of Cambridge, Free School Lane, Cambridge CB2 3RQ, UK 
production of policy knowledge and reflect on their effects on the likely output and orientation of two sites of policy research: universities and think tanks.

Throughout this paper, we employ the term intellectual intervention to refer to cultural artefacts and assemblages that convey a cognitive content-books, articles, reports, blogs, speeches and so on-aimed at informing a debate on an issue of public concern. An accompanying effect of such interventions is to situate individuals or organisations producing them vis-à-vis their audiences and other actors. In that sense, the meaning of an intervention is only intelligible in the setting in which it is uttered and in relation to how others are positioned by it and, in turn, perceive and position the initial 'intervenor' (Baert 2012). Although many types of institutional actors are involved in producing policy-relevant interventions - e.g. consultancies, lobbyists, professional and sectorial organisations - we focus primarily on university departments and think tanks because of the primarily 'public' character of their work rather than catered for advising private clients or (at least overtly) promoting their interests. Nevertheless, we do not seek to demarcate too neatly the contours of these research sites. It has been argued, for instance, that how to define 'think tank' is secondary to describing think-tank-like behaviours and functions (Pautz 2011) and indeed much of what we argue could apply to other kinds of institution, such as non-governmental and multilateral organisations. We have selected universities and think tanks, ultimately, because traditional sources of funding have, under pressures from the 'Mode 2' organisation of knowledge production, undertaken significant organisational transformations that affect the shape of their output.

Many structural elements of institutions shape intellectual production. In this regard, both the sociology of knowledge and neoinstitutionalism have made substantial inroads, especially concerning disciplinary boundaries, regulatory frameworks and path dependencies. For example, Fuller (1991, p. 302) describes how "disciplinary boundaries provide the structure for a variety of functions, ranging from the allocation of cognitive authority and material resources to the establishment of reliable access to some extra-social reality." Similarly, Glaser and colleagues (Gläser et al. 2016) argue that generic governance structures and processes (e.g. legal regulations) affect fields and organisations from their earliest stages. However, this paper will be limited to the key area of modalities of research funding, which, by its very nature, needs to be continually negotiated rather than set in perpetuity at an institution's early stages. We thus address the question: How does the shape of organisational funding affect the type of interventions produced by policy-oriented researchers across contexts?

With that concern in mind, the primary objective of this paper is to provide a novel theoretical and methodological approach for examining organisations that receive funding on a mainly non-profit basis for the purpose of producing intellectual interventions. It explores how context-dependent institutional features shape intellectual products. In doing so, it will show how specific types of interventions - and hence, of knowledge - are likely to be favoured, maintained and enacted in relation to varying funding pressures and organisations' attempts to be seen as intellectually independent. Ultimately, this paper's main contribution is a model for understanding how the processes of intervening and attaining a recognisable position in the policy debate are iterative, and the place of funding modalities within them, especially in relation to an organisation's perceived independence from outside interests.

These reflections are inspired by two recent sources from the sociology of knowledge. First, the Bourdieusian framework developed by Medvetz (2012) for gauging think tanks' liminal place across the fields of the economy, academia, politics and the media. Medvetz highlights the need to recognise that the goals of knowledge-producing organisations are manifold and that their position within one field can affect how actors in others perceive them. For instance, 
a high proportion of corporate backing can risk weakening an organisation's credibility amongst scholars and, conversely, organisations mostly focused on academic products are often disregarded for being politically ineffectual and untimely by participants from other fields. Second, we draw from current developments in the sociology of intellectuals. This literature stresses the need to focus, rather than on the intentions, social characteristics or normative orientation of intellectuals understood as a more or less circumscribed social group, on intellectual products and their effects, regardless of their narrow institutional provenance (Baert 2012; Eyal and Buchholz 2010). This 'performative turn' in our understanding of knowledge production underlines the necessity to think of intellectual interventions as defining those who utter them rather than to delve on the attributes that could determine who counts as intellectual or as an expert in a given public debate.

In addition, this article deploys two concepts, derived loosely from Bourdieusian sociology, to examine the impact of funding modalities in the positioning effects of the interventions of policy research organisations. The first is 'cognitive autonomy.' By this, we mean the capacity of a social actor's judgments to be seen as driven primarily by truth-seeking rather than by the influence of external pressures - in Bourdieu, in relation to the doxa of a relatively autonomous field such as science (see Bourdieu 2001; Swartz 2013). This separates actors whose interventions are evaluated in terms that are to a great degree independent of their social position (e.g. mathematicians) from those whose enmeshment in networks of actors and interests precludes them from being seen as engaging in pure 'truth-seeking' (e.g. politicians). The second, 'epistemic authority,' refers the benefit of an actor's judgments to be (however widely) trusted to provide a reasonable judgement of a state of affairs, one which others can responsibly refer to and base their decisions upon (Pierson 1994; Herbst 2003). In Bourdieusian parlance, epistemic authority is a type of 'symbolic power,' in the capacity of those to yield it to provide an influential view of the world. As shall be shown, the perceived cognitive autonomy of policy actors has effects on how wide their reputation for epistemic authority can aspire to be (see Eyal and Pok 2011), and both factors are, in turn, influenced by the provenance and allocation of research funding.

The remainder of this paper is structured as follows. The next section surveys the literature on the changes in the production of policy-relevant knowledge in the past decades across universities and think tanks in OECD countries. A third part provides a theoretical and methodological framework to understand the implications of varying funding models and sources in the production of policy-relevant intellectual interventions, based on the concepts of 'epistemic authority' and (perceived) 'cognitive autonomy.' A final section reflects on the potential of such a model to understand current trends in the funding of policy-relevant intellectual interventions and their likely positioning effects across audiences.

\section{Changes in Knowledge Production Across Research Contexts}

In recent decades, scholars have noted the rise of a 'new mode of knowledge production' that transcends the organisation of knowledge in disciplines. 'Mode 2', 'post-normal science' or 'post-academic science' describe profound social, cognitive and institutional changes occurring over the last decades, representing an emerging form of knowledge production that is increasingly applied, heterogeneous, transient and socially accountable (Enders 2005). 'Mode 2' includes a broader, more diverse set of practitioners than 'Mode 1' (discipline-based) knowledge production, as it is organised around collaboration on specific, multi-dimensional 
problems and brings together actors from across disciplines, professions and interests. In this new mode, knowledge is created in a great variety of institutions that display a diversity of funding patterns with a wide range of goals, requirements, standards and expectations (Gibbons et al. 1994).

Furthermore, the 'entrepreneurial science' model holds that the convergence of scientific and economic arenas have led researchers to harbour an entrepreneurial ethos and a desire to market their research in order to promote it and secure crucial resources (Albert 2003). Similarly, the literature on the 'academic capitalism' model refers to increasing competition for external funding - e.g. grants, contracts, endowments, student fees - and market activities - e.g. for-profit pursuits, patenting, spin-off companies (Ylijoki 2003). Such proposals relating to the transformation of the functioning and role of research challenge traditional understandings of a well-established order for science and research. This applies not only to innovation-oriented research, but also to decision-oriented strategic research and expertise. Within this view, borders are blurred, not just between disciplines, but also between universitybased academics and other knowledge producers, between basic and applied research, and between the scientific orientation towards the production of new knowledge and the economic rationality of capitalising on such knowledge (Enders 2005). The potential impact of these developments for the allocation of funds for the production of knowledge - and who might be interested in providing them-is difficult to exaggerate.

Given the variety of organisations and institutions intervening in policy matters, there are diverse funding patterns within 'Mode 2', problem-orientated contexts. In this paper, we focus on policy-related research, on account of its orientation towards decision-makers and the public debate, and hence the propensity of actors within it to produce intellectual interventions in many formats.

Thus far, there have been three major levels in which funding has been addressed in the literature on knowledge production: (i) in terms of wider shifts in funding structures, (ii) context-specific, in relation to the utilisation of resources in specific types of research organisation, and (iii) source-specific, in relation to the origin of funds. However, relatively little work has been made to connect these levels, especially from a comparative perspective. For those reasons, in the following, we outline some of the funding trends in two key policy research contexts: (a) university departments and (b) think tanks.

The issue of university research funding has received substantial academic attention. In recent decades, there has been a relative decrease in direct support from governments and research councils (Pohoryles and Cvijetic 2002; UK Universities 2014) and an increase in industrial, charitable and other forms of external funding across OECD countries (Auranen and Nieminen 2010; Connolly 1997; Vincent-Lancrin 2006). An increasing preponderance on funds on the basis of performance and short-term projects has been accompanied by the adoption of mission-oriented and contract-based strategic allocation procedures by research councils and other funding bodies, as well as a greater reliance on student fees (Hydén 2010; OECD 2004; Slaughter and Leslie 1997; Sousa and Brennan 2014). Despite these transformations, public funds are still the primary source for university research. By way of illustration, the mean industry funding of university research in OECD countries in 2003 was just $6 \%$ (Vincent-Lancrin 2006, p. 8). Nevertheless, these changes are often viewed as a threat to research in pure and non-marketable areas, as they are less likely to be supported by private sources (Kelly 2014; Norton 2015). Others argue that funding shifts do not significantly affect actual research practices, as most researchers are adept at balancing scientific and extrascientific interests (Albert 2003; Behrens and Gray 2001). 
Changes in universities have therefore been neither as dramatic nor as consistent as might have been predicted. Universities are still mainly national institutions, and public universities are still largely the dominant form, especially in terms of student enrolment (Auranen and Nieminen 2010; Lebeau et al. 2012). Overall, there are conflicting views concerning the effects of the growth of market pressures on the internal functioning of academia. At one extreme, a radically new market-oriented research culture has emerged (Parker and Jarry 1995; Scott 1997; Ziman 1996), and on the other, there remains space for both traditional academic values and the emergence of counter-trends (Clark 1998; Martin and Etzkowitz 2000). It is thus premature to conclude that broad changes have eroded the traditions and local contexts of specific disciplines and research units. There remains a multiplicity of research practices in academia; researchers are active actors who regulate their responses to change according to their values, interests, objectives and traditions (Cherney et al. 2013; Goodall 2009).

Global influences, while not uniform, do seem to exert pressure on university systems away from a reliance on public funds and core-funding models (Smith 2010; Ylijoki 2003) which may lead to unintended consequences in terms of research outputs and preferred channels and audiences for communicating such research (Braun 1998; Gläser et al. 2010; Hicks 2012). Thus, many of the changes implicit in 'Mode 2' have significantly influenced how institutions are run and how students, employees and users of research relate to each other. In a nutshell, the dominance of 'Mode 2' in university contexts risks eroding the cognitive autonomy of university-based research centres by abrading the distance between patrons, consumers and users and the producers of knowledge.

As in the case of universities, the literature on think tanks emphasises issues of funding and independence. Great variation exists, both regarding the organisations that fund think tanks and their research-ranging from government departments, research councils, charitable trusts, private firms and wealthy individuals - and the perspectives and topics that are considered important to fund by these actors. Sometimes, these interests require positioning an organisation against the prevailing common sense: in contradiction to the government agenda, economic orthodoxy, the wider policy and corporate community, which can favour an adversarial mode of public engagement. Furthermore, unlike most universities, think tanks' reputation is often linked to specific political sectors, which affects what type of funding they can pursue.

Nevertheless, Mirowski and Plehwe (2009) detail cases of think tanks being extremely cautious of external influences that might dilute the perceived cognitive autonomy of their work, sometimes to the extent of actively blocking contributions and involvement of certain sources, because of possible conflicts of interest related either to the nature of the donor or to their overreliance on few funding sources. There are many examples of this: the Canberrabased Development Policy Centre deliberately eschews core funding from the Australian Government in order to critique the latter's international development policies, and even the opaquely-funded and corporate-friendly Adam Smith Institute in the UK claims to have as policy not to receive more than $5 \%$ of their total funding from any single donor. Implicit in these refusals is the idea that certain funding arrangements might compromise the perceived authoritativeness of think tanks to produce autonomous intellectual interventions, and hence damage their epistemic authority. Given the importance of being seen as independent to maintain such authority, funding is a crucial area for the study of think tanks. Indeed, their reliance on sponsors that have their own interest in the policy debate might conceivably skew the content of their interventions and expose them to challenges to their legitimacy - which is exacerbated by the refusal of many think tanks to reveal their sources (McLevey 2014). 
While often the relationships between think tanks and their funders take the form of contracts or commissions circumscribed to specific research and outreach projects, think tanks also seek core funding (e.g. donations, sales of publications) to develop their own research agendas (Ladi 2011). As shall be shown, the space for an organisation to develop its own research agenda can, in turn, cement their 'brand' in a specific policy area, which can help garner further influence and funding (Fraussen and Halpin 2017). Hence, think tanks, despite their typical exemption from delivering profits to shareholders, are not immune from the pressure to appease and attract potential donors, which might have their own aims, such as gaining in-kind resources, producing expert knowledge to support specific policy outcomes or access key actors (e.g. policymakers invited to their events). In Medvetz's (2012) terms, think tanks and their funders might be rather interested in 'converting' capitals from one field into another (e.g. economic into academic and political capital), rather than advancing policy knowledge from a detached perspective.

Inevitably, the links with external bodies raise crucial questions about how research agendas, outcomes and practices are swayed either explicitly or tacitly in think tanks' research conduct (Stone 1996). The trend for funding has been towards short-term, project-specific and result-driven grants (Ricci 1993; Weidenbaum 2010). The effects of this, on the one hand, include a greater focus on organisational efficiency, dissemination and short-term policy issues and legislative agendas. On the other hand, the lack of long-term institutional support increases the influence of donors on research design and outcomes and can distort think tanks' mission and limit their time for analysis, innovation and their ability to attract and retain the best scholars (McGann 2003). Think tanks are thus diverse in terms of funding sources and business models; each negotiates a balance between research, consultancy and advocacy work and their corresponding interventions (e.g. policy reports, op-eds) and adopts strategies that maximise their independence from funders.

This section has considered these contexts in which funding for policy-relevant research might have effects on intellectual outputs, exploring the parallel literatures on each setting. In what follows, we propose a model to understand the process of producing intellectual interventions, with an emphasis on the role of funding arrangements within it and their effects on the intellectual products and the perceived cognitive autonomy of corresponding 'intervenors'. Given the concern of these types of organisation with diverse audiences (generally academia, policymakers, practitioners and the wider public debate), this comparative focus allows for in-depth examination of modes of knowledge production across organisational contexts.

\section{A Theoretico-Methodological Model of Policy-Relevant Intellectual Interventions}

In practice, most interventions require some type of institutional resource or investment, be it in the form of research capacity, time, reputational risk or access to networks of experts or gatekeepers. Hence, the production of interventions often requires prioritising some institutional aims and standards over others-e.g. what issues to focus on, what message is considered important and efficacious, which audiences should be sought, what level of quality-assurance is required, what timeframe is considered convenient and which sponsors are considered jeopardous for an organisation's standing and mission. We focus specifically on how interventions are linked to funding arrangements and structures, given that economic 
resources are a central factor in the above considerations. After all, with limited resources, there are always trade-offs in the production of policy-relevant interventions, both in the shape these take and in their likely effects. As such, tensions between structural conditions and desired outputs are common.

Examining the funding make-up of institutions and shifts in their interventions allows us to consider the priorities and strategies not just of funders but also of knowledge-producers themselves, and how funding itself affects an organisation's positioning. Yet, the influence of changing patterns of research funding at the level of the individual and basic unit has yet to be established. Hence, to steer away from a crudely materialist frame-where funding patterns over-determine the interventions an organisation produces - one needs to consider how researchers position themselves in relation to these structural changes in view of their search for perceived cognitive autonomy and epistemic authority.

In what follows, we propose a comparative theoretico-methodological framework to understand the positioning effects of interventions across contexts, focused on the effect of iterative processes of intellectual production - emphasising funding modalities — on the likely format of interventions. We will further these insights by exploring relevant examples of where such a methodology could be applied, along with reflections on how to probe the effects of funding on the interventions of organisations and their perceived cognitive autonomy across our contexts. Such as design permits examination of how individuals and organisations position themselves at two levels: (i) discursively and (ii) through the formats of their interventions. This section outlines an approach where these two facets of intellectual production are put in a context of continuous (re)positioning in relation to funding.

The intellectual interventions of organisations such as think tanks and university research centres most often take the form of texts - if however, one can also count indicators, statistics and other non-verbal forms (Eyal and Levy 2013). An important part of these, given the publicity the policy debate demands, are made available publicly, produced in various formats and with differing audiences in mind. Documents are, after all, a privileged index of institutional change: for instance, they can give evidence of the establishment or disbandment of research teams. They provide a wealth of data, including policy focus, authors, prevailing narratives of events, formats, language and, depending on degree of transparency, funding sources. As Bowen (2009) claims, although documents are seldom produced in the interest of researchers, they are useful trackers of organisational change. To interpret these changes, we propose a working model of how experts intervene. The diagram below [Diagram 1] showcases the analytical phases of an intellectual intervention, explained further in the following paragraphs.

One caveat must be stressed beforehand. This framework is inspired by ideas that have been applied mainly to individuals. So, while this model is suitable to study organisations, some differences are noticeable. For this reason, a third dimension of overlapping interventions was added - in parentheses - which refers to the positioning effects of each intervention at an aggregate level, both in time and amongst members of an organisation.

To begin, interventions refer to a subject matter, a policy issue, event or state of affairs [A]. What is considered worthwhile to intervene on depends, to mention a few factors, on an organisation's research agenda, what is salient in the public debate, a government's policies, research funding priorities, the interests of trustees and funders and regulatory limits. Thus, any 'intervenor' has a certain space for manoeuvre and constraints that require balancing when deciding what to intervene 'about.' Additionally, as policy issues are situated in a larger context, interventions amount to entering into a 'conversation' with several actors. Over time, 


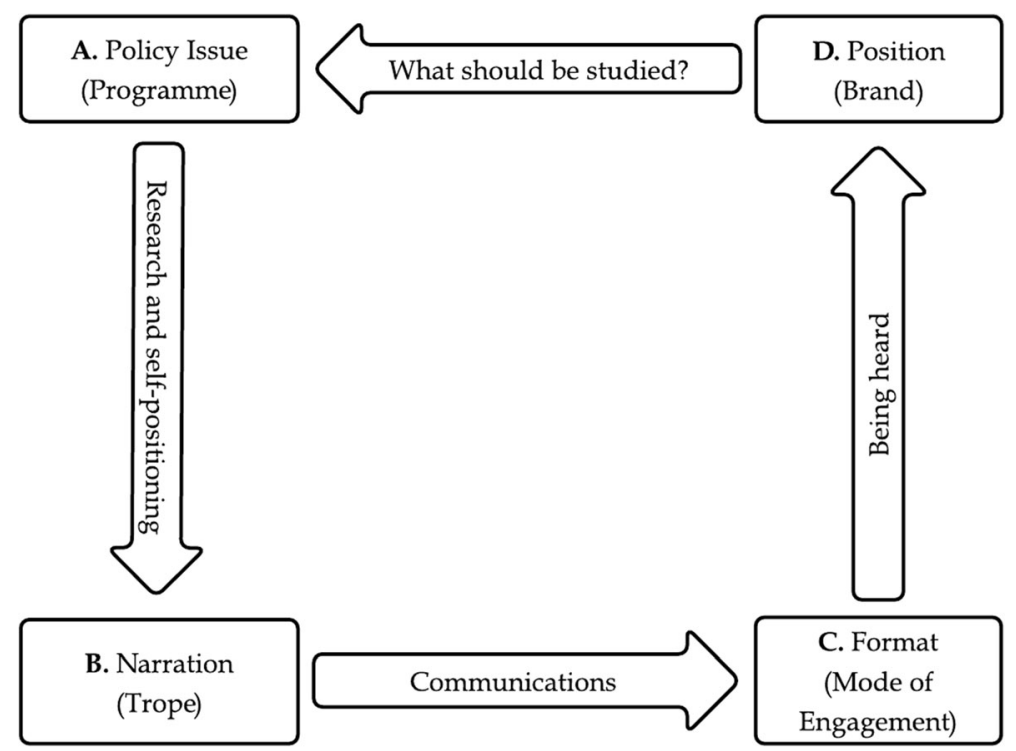

Diagram 1 Phases of an intellectual intervention

a concentration of interventions on a specific issue tends to coalesce into a 'research programme' and a reputation within debates on a specific issue.

By 'narrative' [B], we refer to the substantial content of interventions, which normally entails a description of a state of affairs, a recounting of its causes and policy recommendations. Through this account, a specific understanding of the issues at hand is advanced, while others are ignored or minimised. Theoretically speaking, one could say a narrative weaves a plot that collects disparate elements into an 'intelligible whole', linking together description, conclusions and recommendations. Ultimately, all 'narratives' - even those by the most respected epistemic authorities, as the literature on the production of scientific knowledge reports-leave out some aspects of the social world and guide readers "down specific logical channels, while blocking off others" (Hilgartner 2000, p.9).

We hasten to add, as devising novel policy proposals is taxing, 'interventions' often cite or evoke previous interventions. Repetition, ultimately, is paramount to disseminate an idea and to gain recognition as its champion (Baert 2012). In time, interventions by the same organisation coalesce into 'favoured arguments' - or 'tropes,' in account of the part played by recurrent ideas, 'rhetoric' and 'style.' For instance, while think tanks comment on a variety of issues, they can seek to develop a distinctive form of argumentation across policy areas to strengthen their recognisability. This is conspicuous both for organisations undertaking commissioned research - where the choice of policy problem hinges at least partially on available funding, and hence authors intervene on an often-unplanned range of topics - and for those with core-funding - which presumably have greater control over their policy focus. McLennan (2004), for instance, when describing the work of the British think tank Demos, identifies as its favoured arguments the need for decentralisation, social entrepreneurship and empowering local communities, in areas as distant as education, urban development and the state of the dentistry profession in the UK.

The third point, 'format' [C], refers to 'how' the act of intervening is carried through the means by which knowledge-producing organisations convey their 'narrative' to their 
audiences. This format entails several variables, including timing (e.g. referring to recent or looming events), language (technical, polemic), purported audience (policymakers, public, practitioners), medium (blogs, essays, books, reports) and reference to other actors (academics, politicians, activists, journalists). To be sure, many 'formats' can derive from the same 'narrative', but some are more suitable than others to produce particular effects; in terms of the audiences they reach (e.g. op-eds against technical reports), exhaustiveness (blog posts versus academic books) and tone (pamphlets vis-à-vis econometric forecasts).

Ladi (2011) stresses the distinction between 'communicative' and 'coordinative' discourse - whether an intervention seeks to inform the wider debate or address policymakers directly. Nevertheless, some compromises can be reached between producing an intervention for 'coordinative' or 'communicative' purposes: for instance, through the use of infographics or videos to convey ideas that are otherwise too specialised for larger audiences. In time, an inclination for a particular format in time generate a 'mode of engagement,' a recurrent way of presenting an intervention and, by implication, situating one's public role-e.g. plain-speaking or technical, passionate or aloof, oriented towards a wide public or a specialist niche.

The final point and end-product, [D], an organisation's 'position', relates to how interventions situate an actor amongst others with which they enter into relationships of alliance and competition; that is, how in the process of intervening, the identity of an organisation comes to be perceived by others. This point represents where the accruement of reputation occurs as the by-product of constant interventions - which are, lest we forget, context-specific. Through time, positioning efforts can be understood to represent the search for a recognisable 'brand'. The latter-shorthand for the sedimentary product of several interventions-facilitates, within certain audiences, to obtain funding, attract candidates and gather other resources. In Bourdieusian terms, here the procurement of symbolic capital is visible, where an intellectual position is continuously re-asserted and comes to be recognised.

As we have shown, recurrent interventions inform an organisation's 'brand.' This brand, in turn, and closing the circle, has effects on which policy areas are more likely to be covered and the type of funding an organisation can pursue effectively. For instance, if a think tank is successful in positioning itself as scholarly rigorous, academic research grants become an attractive source; if another is seen as staunch free-market advocates, it might be more inclined to seek support from corporate donors. Moreover, following Medvetz, the ability to muster the latter (corporate donations) can hinder its capacity to obtain the former (academic grants). And while academic grants tend to add to the epistemic authority of an organisation, they seldom can provide the resources for core activities that private donations can.

However, unlike most think tanks, for universities, the accruement of a 'brand' and reputation is to a greater extent independent from the specific content of the interventions by academics working on their aegis. That is partly because academia's (often Mode 1) orientation towards seeking a reputation for autonomy bars a too close coordination of interventions at an institutional level. Furthermore, and the obverse of the dynamics of think tanks, many university researchers are often reluctant to engage in communicative discourse in the fray of contentious policy discussions - given their reliance on sources that require a certain reputation for cognitive autonomy - if also sometimes pressured to do so to justify the 'wider impact' of their work.

For the purpose of identifying where funding arrangements might affect the interventions of a policy research organisation, the main corollary of this model is that transformations of an organisation's position can happen at any of the points outlined above: 
- 'Policy issue' [A]: this aspect of interventions can be affected, for instance, by changes in available funding for tender, the prominence of a policy area, a government's agenda or the perceived emergence of risks (e.g. global warming). For instance, it is worth noting that most think tanks did not have in-house expertise on financial markets before 2008 . The advent of the crisis certainly changed that, facilitated by the emergence of new sources of funding and a growing attention in the public domain for such research. In a similar fashion, the result of the 2016 UK referendum on leaving the European Union has prompted a number of academics and international organisations to concentrate their intellectual output in the implications of this policy decision. In the context of the debate over 'Mode 2,' it is arguable that new actors and patrons can influence the prevalence of funding for certain research topics, perhaps at the expense of those derived from intradisciplinary debates.

- Narrative [B]: This is, in principle, the most resistant aspect of an intervention to funding influences - at least, discounting a crudely materialistic understanding of knowledge producers, where 'intervenors' are primarily swayed by the views of funders. Indeed, such demands are often contested in account of the danger they entail to the perceived cognitive autonomy of intervenors. However, although editorial pressures by funders do exist, it is unlikely for established organisations that face reputational risks to change their 'preferred arguments' too readily - their effects on perceived cognitive autonomy would be too damaging. Nevertheless, for the case of think tanks closely aligned with a political party, certain tropes could be privileged in connection to changes in the policy orientation of a government, or when undergoing movements of personnel. Furthermore, unlike advocacy organisations, researchers who seek epistemic authority across expert audiences might attempt to eschew any ready-made 'trope' in order to be seen as autonomous: this is often the case with some types of government and research council funded research that needs to be perceived as apolitical.

- Format [C]: modes of engagement can change in relation to the publics that are seen as relevant. This is especially conspicuous when available funding depends on reaching particular audiences - for instance, by justifying the relevance of research to funders through media visibility and through social media - which is especially visible in 'Mode 2'. By way of illustration, the rise of altmetrics has provided funders with tools to gauge the impact of research across non-traditional audiences (such as social media), and in time, these tools can conceivably favour certain forms of public engagement (Allen et al. 2014). A greater emphasis on 'impact' in how university-research is assessed has, indeed, effects on the formats and conduits academics employ in their interventions, as the experience of the Research Excellence Framework has shown for the case of British academia (Holmwood 2014).

- Position [D]: As the end-result of the process of intervening, how a changing environment affects the positioning of an organisation can only be obliquely studied through the funding it is likely to attain. For instance, changes in the environment of research organisations can provoke transformations in how their 'brand' is perceived by funders - particularly, their perception of neutrality and scientific rigour. For example, Medvetz (2012) describes how the free-market AEI came to be seen as moderate in the USA, as more vocal alternatives appeared on its right flank, which hurt its changes amongst Conservative donors and drove a change of position in relation to the political field. Similarly, McLevey (2014) illustrates how centrist and right-of-centre think tanks in Canada have come to rely on quite distinct forms of funding — on state funding and private 
sources, respectively. That difference in turn shapes the interventions that are likely to be produced by the think tanks in question — geared, for instance, towards political neutrality and coordinative discourse or, conversely, towards politicisation and communicative discourse.

The aim of this model is to bring together different analytical levels of intellectual interventions, based on the idea that they are both cause and effect of institutional dynamics - they evidence organisational changes and can engender a new 'brand,' which has effects on their future output and the funding avenues they are likely to pursue. Possibly, this model's chief advantage is, however, that it allows incorporating various forms of interventions as data across time. It constructs, as it were, a scaffolding to connect interventions together, highlighting that each utterance is more than a standalone piece but part of an iterative process, accomplished across many platforms. We are aware that this is only the first step of a theoretico-methodological agenda to trace how policy-relevant public interventions are produced, and that indeed funding is but one variable. However, we hope that through the above, we can aid in the development of a common language that facilitates comparative analyses across sites of policy research. In the following and last section, we examine some current trends in the policy research landscape, and its effects on the interventions in view of the above model.

\section{Conclusion}

In line with the focus of the sociology of intellectual interventions on products and their effects, it is important to recognise that each research context has its own logic on which are valued, legitimate products, which is shaped by structural features. Throughout this paper, we have provided examples of how these pressures might affect the process of producing intellectual interventions at different stages of the process, in the understanding that different regimes for the demand and employment for knowledge have effects on the shape of such knowledge (Campbell and Pedersen 2011). Hence, much of the process of producing intellectual interventions varies across and within sites. For example, universities publish in journal articles that are included in academic databases, yet think tanks primarily upload publications to their website or blog, and some think tanks might privilege the production of reports aimed at civil servants and policymakers, while others might privilege intervening in traditional and social media to reach larger publics. These decisions are not innocuous and have effects on the expected audience for their work, their 'impact' and, at the level of positioning, the avenues institutions could pursue at the level of funding.

We have argued that the aim of public interventions is to inform the public debate as widely as possible, which requires at least a modicum of perceived cognitive autonomy-if one is to speak beyond specific political constituencies. The gap between the perceived credibility of different types of knowledge according to their provenance is a strong illustration of this (see Doberstein 2017). In that sense, knowledge production processes must match embedded expectations of the performance and purpose of knowledge. Therefore, the result of successful research practices is the attainment of a 'brand' of cognitive autonomy and epistemic authority, or in other words, (socio-scientific) legitimacy (Williams 2018).

Nevertheless, often that autonomy necessitates a certain distance and specialism that hinders its reach beyond specialists, and hence its capacity to garner sources under 'Mode 
2'. Across both research contexts, we have seen a growing reliance on short-term, impactassessed and project-based funding over core donations. In the case of universities, the impact of this is more 'impact' requirements and further links with business and charitable organisations, which could lead to a diminishing number specialist books and peer-reviewed articles, linked to a larger number of interventions through semi- and non-academic venues, as well as a growing number of reports catered to specific users of knowledge. However, peer-reviewed articles often remain central for the accruement of a position of academic authority, and indeed, their production is a major factor in the allocation of research funding. In the case of think tanks, similar pressures at the level of the format of interventions may apply (barring cases where an organisation necessitates peer-reviewed articles to maintain a reputation for academic rigour). The impact of this in our model is a weaker research agenda, more 'policy issue' variability, more emphasis on dissemination at the level of format and, arguably, a weakening of cognitive autonomy.

Overall, it is worth pondering if less core funding is linked with more heteronomy in relation to donors and hence with weaker epistemic authority. We surmise the answer is yes and no. Yes, in the sense that research agendas are dependent on available grants and their requirements in terms of topic and format (Lamont 2010) - and, if often implicitly, also trope. However, actors depending on core allocation (e.g. government agencies, corporate-funded think tanks) are always at risk of being labelled as being determined by their patrons - which might explain the need of many to garner a reputation for political neutrality and scientific rigour (see Arvidson et al. 2017). In intellectual position-taking, and especially in agonistic public debates such as those pertaining public policy, successes come with drawbacks and weaknesses. However, the main corollary of this model is that the preponderance of 'Mode 2' can often generate a tension between the desired reputation for cognitive autonomy of an organisation and funding requirements for impact and accessibility. The likely end-result of this tendency is a generalised weakening of epistemic authority.

Open Access This article is distributed under the terms of the Creative Commons Attribution 4.0 International License (http://creativecommons.org/licenses/by/4.0/), which permits unrestricted use, distribution, and reproduction in any medium, provided you give appropriate credit to the original author(s) and the source, provide a link to the Creative Commons license, and indicate if changes were made.

\section{References}

Albert, M. (2003). Universities and the market economy: The differential impact on knowledge production in sociology and economics. Higher Education, 45(2), 147-182. https://doi. org/10.1023/A:1022428802287.

Allen, L., Dinsmore, A., \& Dolby, K. (2014). Alternative perspectives on impact: The potential of ALMs and Altmetrics to inform funders about research impact. PLoS Biology, 12(11), e1002003. https://doi. org/10.1371/journal.pbio.1002003.

Arvidson, M., Johansson, H., \& Scaramuzzino, R. (2017). Advocacy compromised: How financial, organizational and institutional factors shape advocacy strategies of civil society organizations. Voluntas: International Journal of Voluntary and Non Profit Organizations. https://doi.org/10.1007/s11266-0179900-y.

Auranen, O., \& Nieminen, M. (2010). University research funding and publication performance-An international comparison. Research Policy, 39(6), 822-834.

Baert, P. (2012). Positioning theory and intellectual interventions. Journal for the Theory of Social Behaviour, 42(3), 304-324. https://doi.org/10.1111/j.1468-5914.2012.00492.x. 
Behrens, T. R., \& Gray, D. O. (2001). Unintended consequences of cooperative research: Impact of industry sponsorship on climate for academic freedom and other graduate student outcome. Research Policy, 30(2), $179-199$.

Bourdieu, P. (2001). Science de la science et réflexivité. Paris: Raisons d'agir.

Bowen, G. (2009). Document analysis as a qualitative research method. Qualitative Research Journal, 9(2), $27-40$.

Braun, D. (1998). The role of funding agencies in the cognitive development of science. Research Policy, 27(8), 807-821. https://doi.org/10.1016/S0048-7333(98)00092-4.

Campbell, J., \& Pedersen, O. (2011). Knowledge regimes and comparative political economy. In D. Béland \& R. Cox (Eds.), Ideas and politics in social science research (pp. 167-190). New York: Oxford University Press.

Cherney, A., Head, B., Boreham, P., Povey, J., \& Ferguson, M. (2013). Research utilization in the social sciences: A comparison of five academic disciplines in Australia. Science Communication, 35(6), 780-809. https://doi.org/10.1177/1075547013491398.

Clark, B. R. (1998). Creating entrepreneurial universities: organizational pathways of transformation. issues in higher education. ERIC. Retrieved from http://www.eric.ed.gov/ERICWebPortal/recordDetail?accno= ED421938

Connolly, L. S. (1997). Does external funding of academic research crowd out institutional support? Journal of Public Economics, 64(3), 389-406. https://doi.org/10.1016/S0047-2727(96)01626-X.

Doberstein, C. (2017). The credibility chasm in policy research from academics, think tanks and advocacy organizations. Canadian Public Policy, 43(4), 299-330.

Enders, J. (2005). Border crossings: Research training, knowledge dissemination and the transformation of academic work. Higher Education, 49(1-2), 119-133.

Eyal, G., \& Buchholz, L. (2010). From the sociology of intellectuals to the sociology of interventions. Annual Review of Sociology, 36(1), 117-137. https://doi.org/10.1146/annurev.soc.012809.102625.

Eyal, G., \& Levy, M. (2013). Economic indicators as public interventions. In T. Mata \& S. Medema (Eds.), The economist as public intellectual (pp. 220-253). London: Duke University Press.

Eyal, G., \& Pok, G. (2011) From a sociology of professions to a sociology of expertise. CAST Workshop on Security Expertise, University of Copenhagen, 6, 15-17.

Fraussen, B., \& Halpin, D. (2017). Think tanks and strategic policy-making: The contribution of think tanks to policy advisory systems. Policy Sciences, 50(1), 105-124.

Fuller, S. (1991). Disciplinary boundaries and the rhetoric of the social sciences. Poetics Today, 12(2), 301-325.

Gibbons, M., Limoges, C., Nowotny, H., Schwartzman, S., Scott, P., \& Trow, M. (1994). The new production of knowledge: The dynamics of science and research in contemporary societies. London: Sage.

Gläser, J., Lange, S., Laudel, G., \& Schimank, U. (2010). The limited use of research evaluation systems for managerial control in universities. In R. Whitley, J. Glaser, \& L. Engwall (Eds.), Reconfiguring knowledge production: Changing authority relationships in the sciences and their consequences for intellectual innovation (pp. 149-183). Oxford: Oxford University Press.

Gläser, J., Laudel, G., \& Lettkemann, E. (2016). Hidden in plain sight: The impact of generic governance on the emergence of research fields. In M. Merz \& P. Sormani (Eds.), The local configuration of new research fields: On regional and national diversity. Sociology of the Sciences Yearbook (vol. 29, pp. 25-43). Springer. https://doi.org/10.1007/978-3-319-22683-5_2.

Goodall, A. H. (2009). Highly cited leaders and the performance of research universities. Res Policy, 38(7), 1079-1092. https://doi.org/10.1016/j.respol.2009.04.002.

Herbst, S. (2003). Political authority in a mediated age. Theory \& Society, 32(4), 481-503.

Hicks, D. (2012). Performance-based university research funding systems. Research Policy, 41(2), $251-261$. https://doi.org/10.1016/j.respol.2011.09.007.

Hilgartner, S. (2000). Science on stage: Expert advice as public drama. Stanford: Stanford University Press.

Holmwood, J. (2014). Sociology's past and futures: The impact of external structure, policy and financing. In J. Holmwood \& J. Scott (Eds.), A handbook of British sociology. London: Palgrave.

Hydén, G. (2010). Mapping the world of higher education and research funders: Actors, models, mechanisms and programs. Copenhagen: Danish Development Research Network and Universities Denmark.

Kelly, A. (2014). The impact of impact on the REF. The Conversation, December. https://theconversation. com/the-impact-of-impact-on-the-ref-35636.

Ladi, S. (2011). Think tanks, discursive institutionalism and policy change. In G. Papanagnou (Ed.), Social science and policy challenges: Democracy, values and capacities. Paris: UNESCO.

Lamont, M. (2010). How professors think: Inside the curious world of academic judgment. Cambridge: Harvard University Press.

Lebeau, Y., Stumpf, R., Brown, R., Lucchesi, M. A. S., \& Kwiek, M. (2012). Who shall pay for the public good? Comparative trends in the funding crisis of public higher education. Compare: A Journal of Comparative and International Education, 42(1), 137-157. https://doi.org/10.1080/03057925.2012.635418. 
Martin, B., \& Etzkowitz, H. (2000). The origin and evolution of the university species. Science and Technology Policy Research Unit (SPRU), Electronic Working Paper Series, Sussex University. Retrieved from http://www.staff.uni-marburg.de/roepke/documents/sewp59.Pdf.

McGann, J. (2003). Ideas and influence: Think tanks, politics and public policy. Cheltenham: Edward Elgar Publishing.

McLennan, G. (2004) Dynamics of transformative ideas in contemporary public discourse, 20022003. Economic and Social Research Council, R000239504. http://doc.ukdataservice.ac.uk/doc/5312 /mrdoc/pdf/q5312uguide.pdf.

McLevey, J. (2014). Think tanks, funding, and the politics of policy knowledge in Canada. Canadian Review of Sociology, 51(1), 54-75.

Medvetz, T. (2012). Think tanks in America. Chicago: University Of Chicago Press.

Mirowski, P., \& Plehwe, D. (Eds.). (2009). The road from Mont Pelerin. The making of the neoliberal thought collective. Cambridge, MA: Harvard University Press.

Norton, A. (2015). Keeping public priorities in public universities. Retrieved from https://theconversation. com/keeping-public-priorities-in-public-universities-40008

OECD. (2004). OECD science, technology and industry outlook 2004. Paris: OECD.

Parker, M., \& Jarry, D. (1995). The McUniversity: Organization, management and academic subjectivity. Organization, 2(2), 319-338.

Pautz, H. (2011). Revisiting the think tank phenomenon. Public Policy and Administration, 26(4), 419-435.

Pierson, R. (1994). The epistemic authority of expertise. PSA: Proceeding of the Biennial Meeting of the Philosophy of Science Association, 1, 398-405.

Pohoryles, J., \& Cvijetic, S. (2002). Internationalization of research. Innovation: The European Journal of Social Science Research, 15(4), 1351-1610. https://doi.org/10.1080/1351161022000042598.

Ricci, M. (1993). The transformation of American politics: The new Washington and the rise of think tanks. New Haven: Yale University Press.

Scott, P. (1997). The changing role of the university in the production of new knowledge. Tertiary Education \& Management, 3(1), 5-14.

Slaughter, S., \& Leslie, L. L. (1997). Academic capitalism: Politics, policies, and the entrepreneurial university. Baltimore: Johns Hopkins University Press.

Smith, K. (2010). Research, policy and funding: Academic treadmills and the squeeze on intellectual spaces. British Journal of Sociology, 61(1), 176-195. https://doi.org/10.1111/j.1468-4446.2009.01307.x.

Sousa, S. B., \& Brennan, J. L. (2014). The UK research excellence framework and the transformation of research production. In Reforming higher education (pp. 65-80). Dordrecht: Springer. https://doi.org/10.1007/97894-007-7028-7 4.

Stone, D. (1996). Capturing the political imagination: Think tanks and the policy process. London: Frank Cass.

Swartz, D. (2013). Symbolic power, politics and intellectuals: The political sociology of Pierre Bourdieu. Chicago: University of Chicago Press.

UK Universities. (2014). The funding environment for universities 2014: research and postgraduate training. Retrieved from: http://www.universitiesuk.ac.uk/policy-and-analysis/reports/Documents/2014/research-andpgr-training.pdf

Vincent-Lancrin, S. (2006). What is changing in academic research? Trends and future scenarios. European Journal of Education, 42(2), 1-27. https://doi.org/10.1177/000271625228300118.

Weidenbaum, M. (2010). The competition of ideas: The world of the Washington think tanks. Piscataway: Transaction Publishers.

Williams, K. (2018). Three strategies for attaining legitimacy in policy knowledge: coherence in identity, process and outcome. Public Administration, 1-17. https://doi.org/10.1111/padm.12385.

Ylijoki, O.-H. (2003). Entangled in academic capitalism? A case-study on changing ideals and practices of university research. Higher Education, 45(3), 307-335.

Ziman, J. (1996). "Postacademic science": constructing knowledge with networks and norms. Science Studies, 1, 67-80. 